\title{
Enhancement of endothelial nitric oxide synthase production reverses vascular dysfunction and inflammation in the hindlimbs of a rat model of diabetes
}

\author{
A. Riad • D. Westermann - S. Van Linthout • Z. Mohr • \\ S. Uyulmaz • P. M. Becher • H. Rütten • P. Wohlfart • \\ H. Peters • H.-P. Schultheiss • C. Tschöpe
}

Received: 13 May 2008 / Accepted: 21 July 2008 / Published online: 30 September 2008

(C) Springer-Verlag 2008

\begin{abstract}
Aims/hypothesis Reduced bioavailability of nitric oxide (NO) is a hallmark of diabetes mellitus-induced vascular complications. In the present study we investigated whether a pharmacological increase of endothelial NO synthase (eNOS) production can restore the impaired hindlimb flow in a rat model of severe diabetes.

Methods A model of diabetes mellitus was induced in male Sprague-Dawley rats by a single injection of streptozotozin. Rats were treated chronically with the eNOS transcription enhancer AVE3085 (10 mg [kg body weight $]^{-1}$ day $^{-1}$; p.o.) or vehicle for 48 days and compared with controls. Endothelial function and arterial BP were investigated in vivo using an autoperfused hindlimb model and TIPcatheter measurement, respectively. Protein production of eNOS, total and phosphorylated vasodilator-stimulated phosphoprotein (VASP) were assessed in their quadriceps muscle tissue, whereas cyclic GMP (cGMP) concentrations
\end{abstract}

A. Riad $\cdot$ D. Westermann $\cdot$ S. Van Linthout $\cdot$ Z. Mohr $\cdot$

S. Uyulmaz $\cdot$ P. M. Becher $\cdot$ H.-P. Schultheiss $\cdot$ C. Tschöpe $(\triangle)$

Department of Cardiology and Pneumology,

Charité Universitätsmedizin Berlin,

Campus Benjamin Franklin,

Hindenburgdamm 30,

12206 Berlin, Germany

e-mail: carsten.tschoepe@charite.de

H. Rütten · P. Wohlfart

Sanofi-Aventis Pharma,

Frankfurt/Main, Germany

H. Peters

Department of Nephrology,

Charite Universitätsmedizin Berlin,

Campus Mitte,

Berlin, Germany were assessed in blood plasma. RNA levels of intracellular and vascular cell adhesion molecules (ICAM-1 and VCAM-1) were measured by real-time PCR.

Results Untreated diabetic rats showed significantly reduced quadriceps muscle contents of eNOS (-64\%) and phosphorylated VASP $(-26 \%)$ protein associated with impaired vascular function (maximum vasodilatation: $-30 \%, p<0.05$ ) and enhanced production of ICAM-1 (+121\%) and VCAM-1 $(+156 \%)$. Chronic treatment with AVE3085 did not alter arterial BP or severe hyperglycaemia, but did lead to significantly increased production of eNOS $(+95 \%)$, cGMP $(+128 \%)$ and VASP phosphorylation $(+65 \%)$ as well as to improved vascular function $(+36 \%)$ associated with reduced production of ICAM-1 (-36\%) and VCAM-1 (-58\%). Conclusions/interpretation In a rat model of severe diabetes, pharmacological enhancement of impaired eNOS production and NO-cGMP signalling by AVE3085 restores altered hindlimb blood flow and prevents vascular inflammation.

Keywords Diabetes mellitus · Endothelial dysfunction . Inflammation $\cdot$ Nitric oxide

$\begin{array}{ll}\text { Abbreviations } \\ \text { cGK } & \text { cGMP-dependent protein kinase } \\ \text { cGMP } & \text { cyclic GMP } \\ \text { eNOS } & \text { endothelial NO synthase } \\ \text { ICAM-1 } & \text { intracellular cell adhesion molecule-1 } \\ \text { iNOS } & \text { inducible NO synthase } \\ \text { KHS } & \text { Krebs-Henseleit solution } \\ \text { NO } & \text { nitric oxide } \\ \text { p-VASP } & \text { phosphorylated VASP } \\ \text { SD } & \text { non-diabetic, vehicle-treated Sprague- } \\ & \begin{array}{l}\text { Dawley rats } \\ \text { non-diabetic eNOS enhancer-treated } \\ \text { SD-eNOS }\end{array} \\ & \text { Sprague-Dawley rats }\end{array}$




$\begin{array}{ll}\text { SGC } & \begin{array}{l}\text { soluble guanylyl cyclase } \\ \text { streptozotozin-diabetic, vehicle-treated } \\ \text { Sprague-Dawley rats } \\ \text { streptozotozin-diabetic, eNOS enhancer- } \\ \text { treated Sprague-Dawley rats } \\ \text { STZ-eNOS }\end{array} \\ \text { VASP } & \begin{array}{l}\text { vasodilator-stimulated phosphoprotein } \\ \text { vascular cell adhesion molecule-1 }\end{array}\end{array}$

\section{Introduction}

Cardiovascular complications are the most common cause of morbidity and mortality in diabetes mellitus [1]. Reduced bioavailability of the signalling molecule nitric oxide (NO) constitutes a hallmark of diabetes-induced micro- and macro-angiopathy [2-4]. There is a solid body of evidence indicating that NO critically regulates vascular tone, including endothelial-dependent vasodilatation. Furthermore, endothelialderived NO is a key regulator for endothelial cell growth, migration, inflammation, vascular remodelling and angiogenesis [5]. Serving as a paracrine-signalling molecule, NO diffuses to smooth muscle and binds to haem groups of an $\alpha / \beta$ heterodimer soluble guanylyl cyclase (sGC), which in turn converts GTP to cyclic GMP (cGMP) and activates cGMPdependent protein kinases (cGKs) [6]. Studies in mice have demonstrated that a knockout of the $c G k 1$ gene leads to a complete disruption of the NO-cGMP pathway in the vascular smooth muscle, thus supporting the emerging role of this kinase in the executing of $\mathrm{NO}$ actions. One key substrate for cGMP-dependent GKs is the vasodilator-stimulated phosphoprotein (VASP). This protein is produced in many cell types including smooth muscle and endothelial cells [7]. Its phosphorylation has been used as an endogenous biomarker for monitoring the NO-stimulated $\mathrm{sGC}-\mathrm{cGK}$ pathway and endothelial integrity [8].

Evidence for the importance of endothelial nitric oxide synthase (eNOS) in the regulation of NO bioavailability is based on a variety of studies in animals and humans, which have demonstrated that eNOS is able to produce both NO and oxidative stress depending on its type of electron transfer [5]. Endothelial NO release plays among other things an important role in inhibition of inflammatory responses in a variety of diseases [9].

Since diabetes is considered to be at least in part an inflammatory condition, adhesion molecules have attracted considerable attention. Indeed, leucocyte adhesion and infiltration to the vessel wall are crucial for initiating the inflammatory process [10]. We have shown previously that enhanced diabetes-induced production of inflammatory markers such as cytokines and cell adhesion molecules are associated with endothelial dysfunction [11], which is a strong predictor of cardiovascular events [12].
While low eNOS levels have been found in diabetic aortic, renal and heart tissues [13-15], it remains yet unknown whether or not the NO-cGMP signalling axis can be reconstituted by an enhancement of eNOS production under these conditions. In the present study we investigated the hypothesis that pharmacological enhancement of eNOS production with AVE3085, a novel eNOS enhancer, is sufficient to activate the NO-cGMP axis, attenuate inflammatory response, and improve peripheral endothelial function in a rat model of diabetes.

\section{Methods}

Chemicals and reagents AVE3085, a novel eNOS enhancer, was synthesised at Sanofi-Aventis (Industriepark Höchst, Frankfurt, Germany). This compound has been shown to activate cellular eNOS transcription in the human endothelial cell line EA.hy 926 stably transfected with a $3.5 \mathrm{~kb}$ human eNOS promoter fragment, having an $\mathrm{EC}_{50}$ value of $410 \mathrm{nmol} / \mathrm{l}$, and to increase NO release from primary human endothelial cells. All other biochemical reagents were of the highest analytical purity obtainable and were purchased from Sigma (Deisenhofen, Germany).

Animals and treatment Experiments were conducted in 8-week-old male Sprague-Dawley rats (300-320 g; Charles River, Sulzfeld, Germany). Rats were housed under standard conditions $\left(20^{\circ} \mathrm{C}, 12 \mathrm{~h}\right.$ light-dark cycle) and given free access to standard chow and tap water. The experimental procedures were performed according to the Guide for the Care and Use of Laboratory Animals published by the US National Institutes of Health (NIH Publication No. 85-23, revised 1996). Diabetes mellitus was induced by a single injection of streptozotozin $(70 \mathrm{mg} / \mathrm{kg}$, i.p.) dissolved in citric acid-trisodium citrate buffer $(0.1 \mathrm{~mol} / \mathrm{l}, \mathrm{pH} 4.5)$. Diabetes induction was considered to be successful when blood glucose levels were $>16.65 \mathrm{mmol} / \mathrm{l}$ on day 5 . These Sprague-Dawley rats were randomly separated into four groups $(n=8$ each): (1) a non-diabetic, vehicle-treated group (SD); (2) a nondiabetic group treated with the eNOS enhancer AVE3085 (10 mg/kg body weight, per os) for 48 days (SD-eNOS); (3) a diabetic, vehicle-treated group (STZ); and (4) a diabetic group treated with AVE3085 (10 mg/kg body weight, p.o.) for 48 days (STZ-eNOS). That dose of AVE3085 was chosen since it does not influence the arterial BP in streptozotocininduced diabetic rats. Vehicle-treated non-diabetic and diabetic groups served as normoglycaemic and diabetic controls. For the vehicle, a 10\% $\beta$-cyclodextrane (wt/vol.) solution was used.

In vivo assessment of vascular function and left ventricular $B P$ in vivo For in vivo assessment of vascular function, we used the autoperfused hindlimb model in the rat as 
described previously [16-18]. Briefly, the rats were anaesthetised (chloral hydrate, $400 \mathrm{mg} / \mathrm{kg}$ body weight, i.p.), intubated and mechanically ventilated. For assessment of left ventricular BP, a 2.0 French TIP-catheter (Millar Instruments, Houston, TX, USA) was placed in the left ventricle via the right carotid artery as described previously [17]. For assessment of vascular function, an extracorporeal catheter system was placed under aseptic conditions between the left carotid artery and the right femoral artery using polyethylene catheters. An integrated roller peristaltic pump (Minipuls 3; Abimed, Langenfeld, Germany), which delivered blood from the left carotid artery, enabled the perfusion through the femoral artery into the left hindlimb. After $20 \mathrm{~min}$ of perfusion, the pressure baseline was recorded. In order to induce endothelial-dependent vasodilatation, three different volumes of Krebs-Henseleit solution (KHS) $(80,200$ and $600 \mu \mathrm{l} / \mathrm{kg})$ were administered into the femoral artery via a three-way-gain integrated into the catheter system. The area of pressure decrease (integral [I in $\mathrm{mmHg} \times \mathrm{s}]$ ) after the administration of KHS was analysed as an index of the degree of vasodilatation.

Assessment of endothelial function in isolated aortic rings Endothelial function in isolated aortic rings was measured as previously described [19]. In brief, thoracic aortas from SD, SD-eNOS, STZ and STZ-eNOS rats were rapidly excised and cut into rings $2-3 \mathrm{~mm}$ in length for organ-chamber experiments. The rings were then mounted on platinum hooks in modified KHS solution (modified by addition of heparin [1000 IU/l]. Tension was gradually adjusted to $2 \mathrm{~g}$ over $1 \mathrm{~h}$. The solution in the bath was maintained at $37^{\circ} \mathrm{C}$ with a gas mixture of $5 \% \mathrm{CO}_{2}$ and $95 \%$ $\mathrm{O}_{2}$. After equilibration and submaximal precontraction with phenylephrine $(0.05 \mu \mathrm{mol} / \mathrm{l})$, relaxation to increasing concentrations ( $1 \mathrm{nmol} / 1$ to $1 \mu \mathrm{mol} / \mathrm{l})$ of the endotheliumdependent vasodilator acetylcholine was performed to obtain cumulative concentration-response curves.

Tissue preparation After a measurement of vascular function, tissue samples were removed from the non-perfused quadriceps muscle immediately. Isolated muscle tissues were snap frozen in liquid nitrogen and stored at $-80^{\circ} \mathrm{C}$ for molecular biological and immunohistological analyses.

Muscle protein production of eNOS, total VASP and phosphorylated VASP Western blot analyses were performed using $15 \mu \mathrm{g}$ (eNOS) and $20 \mu \mathrm{g}$ (total VASP and its active phosphorylated [p]-VASP Ser239) of protein for each sample. The reaction was carried out using primary antibodies raised against eNOS (BD Bioscience, San Jose, CA, USA; $1: 2,000$ ), total VASP (Axxora, Nottingham, UK; 1:1,000) and p-VASP (Cell Signaling, Boston, MA, USA; $1: 1,000)$. Specific protein bands were detected by a chemiluminescence reaction (ECL; Amersham, UK), followed by quantitative analysis of the intensity of the bands by dedicated software (TINA 2.0; Raytest, Straubenhardt, Germany). Equal protein loading was confirmed by gel staining with SimplyBlue Safestain (Invitrogen, Carlsbad, CA, USA) after SDS-PAGE as previously described [20].

Plasma cGMP concentrations Plasma cGMP levels were measured using an ELISA kit (BioLinx; Dynatech Laboratories, Chantilly, VA, USA) according to the manufacturer's instructions, as described previously [21]. Briefly, samples, standards and peroxidase-labelled cGMP conjugate were transferred to a microplate precoated with a cGMP-specific antibody. After the addition of substrate, optical density was read at $450 \mathrm{~nm}$ using an automated plate reader (MRX II; Dynex Technologies, Frankfurt am Main, Germany). The results are expressed in $\mathrm{fmol} / \mathrm{ml}$.

Real-time RT-PCR As has already been described [16], gene expression of intracellular cell adhesion molecule-1 (Icam1) and vascular cell adhesion molecule-1 (Vcam1) and inducible NO synthase (iNos, also known as Nos2) was assessed by TaqMan quantitative real-time RT-PCR (ABI PRISM 7000 Sequence Detection System software version 1.0; Perkin Elmer, Boston, MA, USA). Total RNA was isolated from each quadriceps muscle and cDNA was generated. Gene expression was normalised in relation to the production of the housekeeping gene for 18S, purchased from Applied Biosystems (Foster City, CA, USA).

Immunostaining of nitrotyrosine Cardiac production of nitrotyrosine were performed as previously described [22]. In brief, detection of nitrotyrosine staining was performed using a rabbit anti-nitrotyrosine (1:75; Sigma) antibody in conjunction with the EnVison + system (DAKO, Carpenteria, CA, USA). For quantitative analysis of nitrotyrosine production, the area fraction of nitrotyrosine was measured by digital image analysis as described previously [22].

Lipid peroxidation activity Lipid peroxidation activity was measured using the commercially available colorimetric assay kit Bioxytech LPO-586 (Oxis International, Portland, OR, USA), as previously described [22]. Briefly, $150 \mu \mathrm{l}$ of protein extracts were used for measurement of malondialdehyde (MDA) and 4-hydroxyalkenals (HAE), considered as indicators of lipid peroxidation, as described in the manufacturer's directions for use. For the calculation of lipid peroxidation, samples were applied to a MDA standard curve and normalised to the relative protein content.

Statistical analysis Statistical analysis was performed using the SPSS software Version 12.0. All data are pictured as mean \pm SEM. Statistical differences were assessed by using 
the Kruskal-Wallis test in conjunction with the MannWhitney $U$ test. Differences were considered statistically significant at a value of $p<0.05$.

\section{Results}

Basic animal characteristics As shown in Table 1, systolic BP, blood glucose levels and body weight were monitored in all of the studied animals. Under normoglycaemic conditions none of the basic characteristics differed significantly between SD and SD-eNOS rats. Forty-eight days after streptozotocin injection, blood glucose was found to be markedly increased in the untreated diabetic animals, while body weight was significantly lower than in nondiabetic controls. Treatment of diabetic rats with the eNOS enhancer AVE3085 did not show any significant further influence on the animals' body weights and blood glucose levels when compared with levels of the untreated diabetic group (Table 1).

Muscle protein production of eNOS, total VASP and $p$-VASP Forty-eight days after induction of diabetes mellitus, quadriceps muscle tissues showed a significantly decreased eNOS protein production $(-64 \%, p<0.05)$ compared with normoglycaemic controls (Fig. 1). The eNOS protein production of SD and SD-eNOS rats did not differ significantly. As anticipated, treatment with AVE3085 led to an enhancement of eNOS production $(+95 \%, p<0.05)$ in diabetic rats compared with untreated diabetic controls in diabetic quadriceps muscle. To analyse the production of activated VASP as a downstream marker of the endogenous activity of the NO-cGMP signalling cascade, we measured the ratio of p-VASP to total VASP protein in the quadriceps muscle. As shown in Fig. 2a, p-VASP protein production was significantly reduced $(-26 \%, p<0.05)$ in untreated diabetic animals when compared with normoglycaemic controls. Again, p-VASP production was more than normalised by treatment with AVE3085 in the diabetic

Table 1 Basic animal characteristics

\begin{tabular}{lllll}
\hline Variable & \multicolumn{2}{l}{ Rat group } & & \\
\cline { 2 - 5 } & SD & SD-eNOS & STZ & STZ-eNOS \\
\hline Body weight $(\mathrm{g})$ & $36 \pm 12$ & $369 \pm 15$ & $258 \pm 4^{*}$ & $251 \pm 6^{* \dagger}$ \\
$\begin{array}{c}\text { Blood glucose } \\
(\mathrm{mmol} / \mathrm{l})\end{array}$ & $4.2 \pm 0.2$ & $4.4 \pm 0.3$ & $>30.5$ & $>30.5$ \\
$\begin{array}{c}\text { Arterial systolic } \\
\text { pressure (mmHg) }\end{array}$ & $95 \pm 4$ & $99 \pm 6$ & $76 \pm 7^{*}$ & $80 \pm 6^{* \dagger}$ \\
\hline
\end{tabular}

Means \pm SEM

${ }^{*} p<0.05$ vs $\mathrm{SD} ;{ }^{\dagger}$ non-significant vs $\mathrm{STZ}(n=8$ per group)

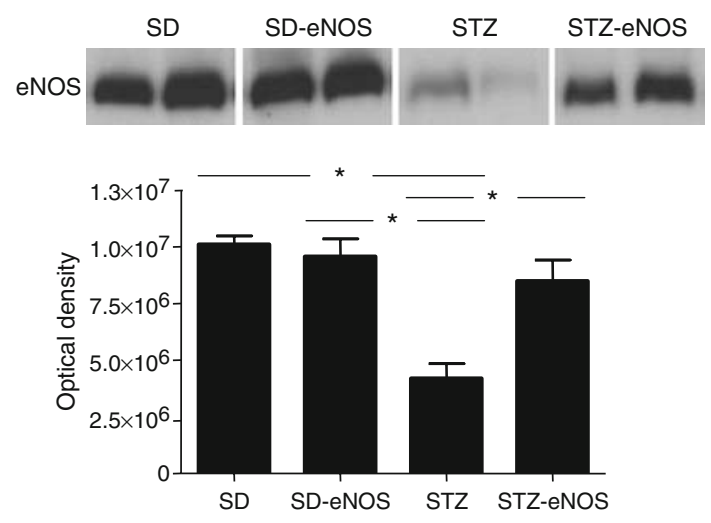

Fig. 1 eNOS protein production in quadriceps muscle. eNOS production was measured 48 days after streptozotocin injection using western blot analysis. Means \pm SEM. ${ }^{*} p<0.05$ ( $n=4$ per group). Two representative blots from each group are depicted

group, i.e. it was $65 \%$ higher than in the untreated diabetic rats $(p<0.05)$ (Fig. 2a). Under normoglycaemic conditions, AVE3085 enhancement did not lead to a significant difference of VASP activation between SD and SD-eNOS rats.
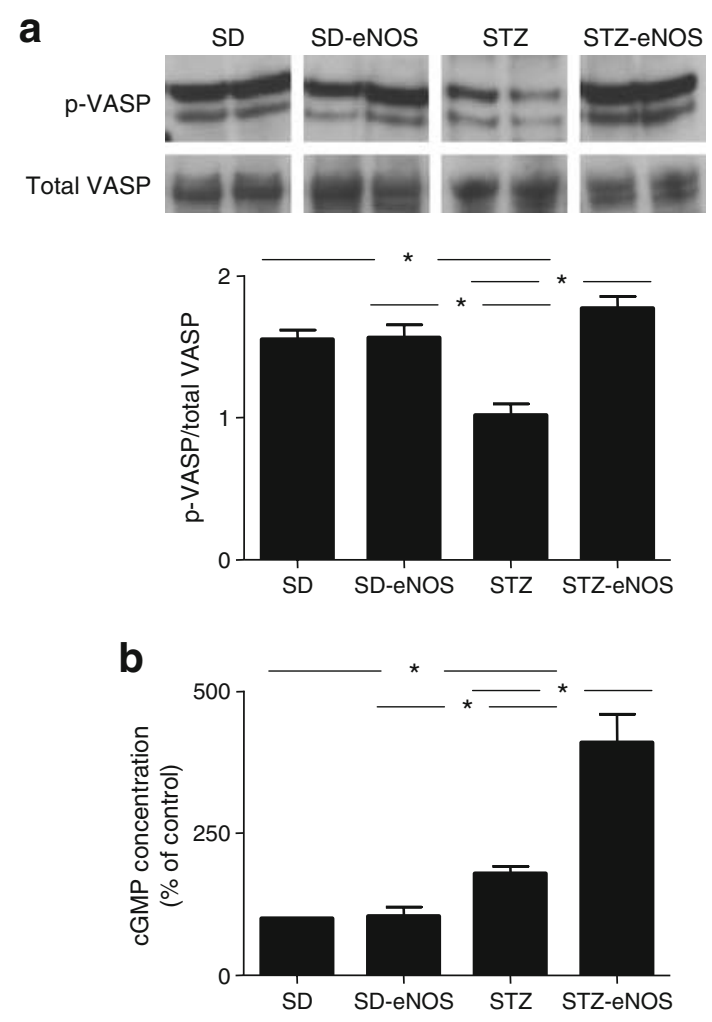

Fig. 2 Phosphorylation of VASP and cGMP concentration. a p-VASP and total VASP protein productions were measured in quadriceps muscles 48 days after diabetes induction using western blot analysis. Means \pm SEM. ${ }^{*} p<0.05$ ( $n=8$ per group). Two representative blots from each group are depicted. b Plasma levels of cGMP were measured by ELISA 48 days after streptozotocin injection. Means \pm SEM. ${ }^{*} p<0.05(n=8$ per group) 
Plasma cGMP concentrations Body cGMP levels are another indicator of endogenous eNOS signalling activity. In line with the results on p-VASP, plasma cGMP levels were significantly increased in the AVE3085-treated diabetic animals in comparison with the untreated diabetic group $(+128 \%, p<0.05)$ (Fig. 2b). Among untreated hyperglycaemia groups, plasma cGMP concentrations were already approximately $80 \%$ higher than in the normoglycaemic controls $(p<0.05)$. Under normoglycaemic conditions there were no significant changes regarding the cGMP concentrations between SD and SD-eNOS rats.

Endothelial function To examine whether beneficial downstream effects after treatment with AVE3085 may have a consequence regarding vascular function, we measured endothelial-dependent vasodilatation in vivo using the autoperfused hindlimb model and ex vivo by analysing isolated aortic rings in an organ chamber. As shown in Fig. 3a, endothelial-dependent vasodilatation, which was induced by induction of shear stress in the STZ group, was significantly reduced at all doses of KHS applied (80, 200 and $600 \mu 1 / \mathrm{kg})$ compared with the SD group $(-43 \%,-42 \%$ and $-30 \%$, respectively, $p<0.05)$. Endothelial-dependent vasodilatory response was significantly improved and almost completely restored in AVE3085-treated diabetic rats compared with the untreated group at all doses of KHS $(+70 \%,+41 \%$ and $+36 \%, p<0.05)$. As shown in Fig. $3 \mathrm{~b}$, in line with our findings from the in vivo assessment, endothelial-dependent vasodilatation of aortic rings induced by acetylcholine was significantly reduced in STZ rats when compared with SD controls. In addition, endothelial-dependent vasodilatation of STZ-eNOS rats was significantly improved when compared with STZ rats. Vasodilatation induced by acetylcholine between SD and SD-eNOS rats did not differ significantly.

Muscle production of nitrotyrosine and iNOS and lipid peroxidation activity Impaired endothelial function in STZ rats was associated with increased oxidative stress indexed by significantly increased contents of nitrotyrosine protein and iNos mRNA in the quadriceps muscle when compared with normoglycaemic SD and SD-eNOS rats (Fig. 4a,b). Improved endothelial function produced by pharmacological enhancement of eNOS was associated with significantly reduced contents of both nitrotyrosine and iNOS nearly to basal level of those from SD rats. Lipid peroxidation activity was significantly increased in STZ rats when compared with SD and eNOS rats. Pharmacological enhancement of eNOS led not to a significantly changed lipid peroxidation activity, but to a directional decrease of this source of oxidative stress, when compared with STZ rats.

Muscle $m R N A$ production of Icaml and Vcam1 Impaired hindlimb flow in rats with diabetes was associated with
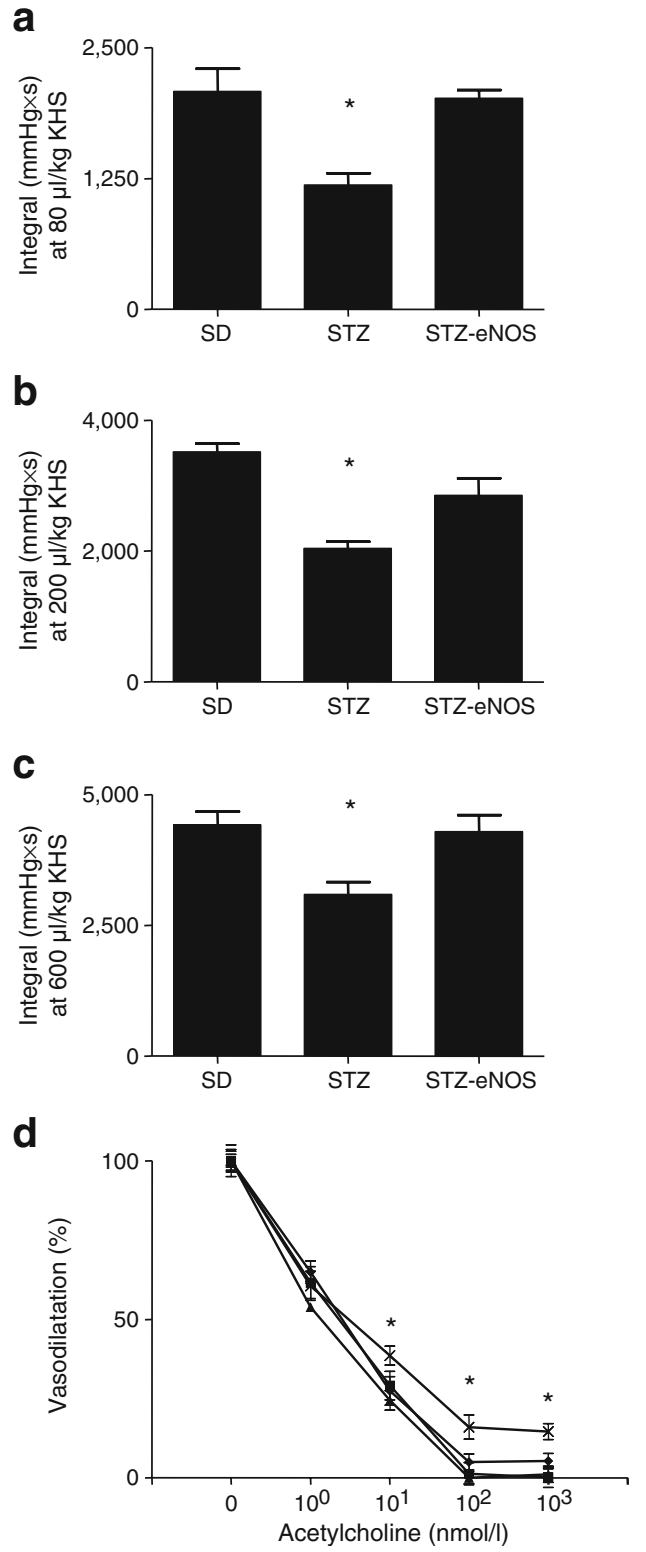

Fig. 3 Endothelium-dependent vasodilatation. a, b, c Flow-mediated endothelium-dependent vasodilatation elicited by administration of KHS (a 80 , b 200 and c $600 \mu \mathrm{l} / \mathrm{kg}$ ) displayed as the integral of pressure decrease $(\mathrm{mmHg} \times \mathrm{s})$. Values are means $\pm \mathrm{SE}\left(n=8\right.$ per group). ${ }^{*} p<0.05$ STZ vs SD and STZ-eNOS. d Acetylcholine-induced vasodilatation in aortic rings. Values are means $\pm \mathrm{SE}$ ( $n=8$ per group). Black squares, SD; black triangles SD-eNOS; crosses, STZ; black diamonds, STZ-eNOS. $* p<0.05 \mathrm{STZ}$ vs SD, SD-eNOS and STZ-eNOS

significant reductions in Icam1 and Vcam1 mRNA expression in quadriceps muscle tissue when compared with values of the normoglycaemic controls (ICAM-1: $+121 \%$, VCAM-1: $+156 \%, p<0.05$ ) (Fig. 5). Treatment with AVE3085 lowered both Icam-1 and Vcam-1 mRNA production significantly, in comparison with values of untreated diabetic rats $(-36 \%$ and $-58 \%$, respectively, $p<0.05)$. 


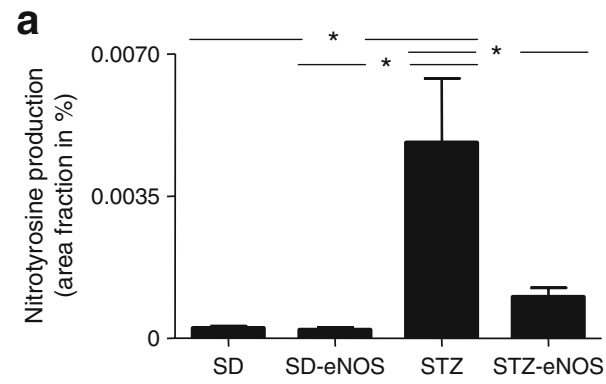

b

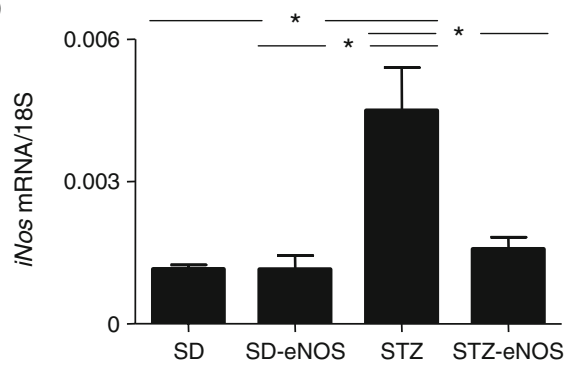

C

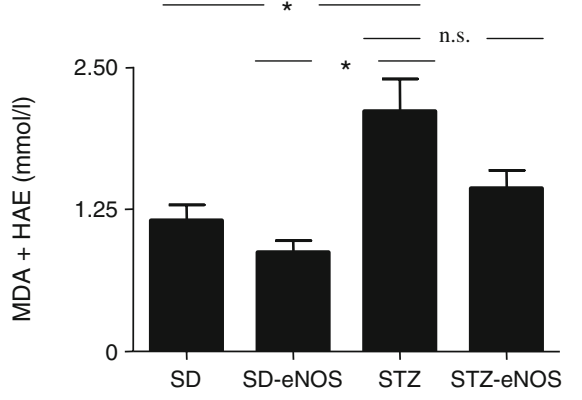

Fig. 4 Nitrotyrosine protein production (a), iNos mRNA expression (b) and lipid peroxidation activity (c) in the quadriceps muscle was measured by immunostaining, RT-PCR and a commercial assay kit, respectively. Means \pm SEM ( $n=8$ per group). ${ }^{*} p<0.05$; n.s. not significant

\section{Discussion}

Here we have shown that pharmacological enhancement of eNOS production via AVE3085 is sufficient to restore the impaired NO-cGMP-VASP axis in the hindlimbs of severely diabetic animals. Improvement in NO-cGMP signalling was paralleled by a significant reduction of vascular inflammatory markers and an improvement of endothelial function. Levels of hyperglycaemia and systolic BP remained unchanged. Furthermore, under normoglycaemic conditions, pharmacological enhancement of eNOS did not affect either endothelial function or the cGMP-VASP axis or the production of oxidative stress. AVE3085 and its derivative AVE9488 belong to a new group of molecules which has already been used in several experimental settings aimed at stimulating eNOS production in various cell types [23]. AVE3085 activates cellular eNOS transcription in the human endothelial cell line EA.hy 926 and increases NO release from primary human endothelial cells.

Recent findings suggest that eNOS regulation is abnormal in diabetes, resulting in a direct contribution by eNOS to vascular superoxide production [24]. However, the regulation of eNOS production in diabetes mellitus is a subject of intense investigation and discussion. Several studies demonstrated decreased eNOS production under diabetic conditions in several tissues. A recent study in streptozotocin-induced diabetic rats could show a decreased renal eNOS protein production 4 weeks after diabetes induction [15]. In addition, reduced eNOS mRNA was found to be present in aortic and myocardial tissues from diabetic rats [13]. There is growing evidence for an emerging role of $\mathrm{NO}$ derived from eNOS in vascular defence against cardiovascular diseases [5]. This is in agreement with our findings, which also show markedly decreased eNOS protein production in streptozotocininduced diabetic quadriceps muscles. But long-term treatment with AVE3085 led to a significant increase of eNOS protein production in diabetic quadriceps muscle tissues without any changes in BP.

To investigate whether increased eNOS production by AVE3085 indeed resulted in improved endogenous NOcGMP signalling, we analysed both cGMP-dependent VASP phosphorylation in quadriceps muscle and plasma cGMP concentrations. VASP is a specific substrate of the cGK-1 in several cell lines including endothelial cells, which is activated by NO $[5,25]$. In agreement with others, who also found reduced VASP phosphorylation in plasma
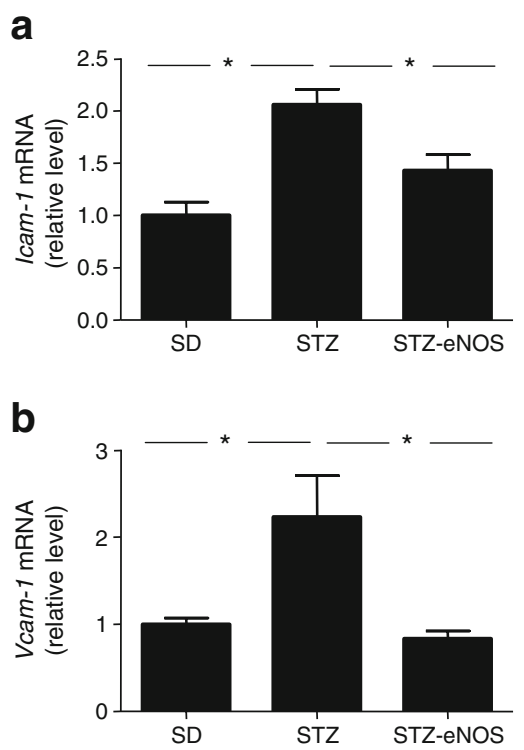

Fig. 5 Expression of Icam-1 (a) and Vcam-1 (b) mRNA was measured by real-time RT-PCR in quadriceps muscle 48 days after diabetes induction and was normalised to $18 \mathrm{~S}$ rRNA. Means \pm SEM ( $n=8$ per group). ${ }^{*} p<0.05$ 
of STZ-diabetic rats [26], the active p-VASP [7] was decreased in peripheral diabetic muscle tissue. Behind its behaviour as a marker for NO signalling, VASP has been shown to play emerging roles in cytoskeleton remodelling [27]. Corresponding to the increased VASP phosphorylation with eNOS production enhancement $(+26 \%)$, plasma concentrations of cGMP were significantly higher and, as viewed relatively, even more highly elevated in the diabetic animals that had undergone AVE3085 treatment $(+126 \%)$. In untreated diabetic animals, a more moderate increase in plasma cGMP levels was observed. This probably reflects the body's whole cGMP production, it may derive from other sources, e.g. the anti-natriuretic peptide as well, and it probably does not reflect any impaired hindlimb NO-cGMP signalling in diabetes. A marked increase in both p-VASP and plasma cGMP demonstrated together that AVE3085 not only enhances eNOS production but as well reconstitutes NO bioavailability in severe long-term diabetes.

A main effect of NO-activated release of cGMP is the dilatation of arterial vessels. Therefore we measured in vivo peripheral endothelial function in the femoral artery and ex vivo endothelial function in isolated aortic rings. In agreement with our previous studies $[11,16]$ and with that of others [18] we also demonstrated under both in vivo and ex vivo conditions the presence of an impaired endothelial function under streptozotocin-diabetic conditions. Under diabetic conditions, endothelial dysfunction is a phenomenon that is often recognised in clinical and experimental settings [28, 29]. It predicts, strongly and independently, adverse cardiovascular events and a long-term outcome [30]. The clinical implications of endothelial dysfunction and the association between endothelial dysfunction and cardiovascular events are well established and have often been reviewed [12]. A precise identification of the underlying mechanisms that lead to endothelial dysfunction still remains the subject of intensive investigation. Here, we demonstrated that the activation of eNOS may lead to an improved endothelial function despite the changes in arterial BP and hyperglycaemia. Since this has been associated with an enhanced cGMP and p-VASP expression, our data suggest that these proteins are indeed involved in the vasodilatory effects of AVE3085 under diabetic conditions.

Since a solid body of evidence suggests that oxidative stress is a main trigger for the development of vascular damage under diabetic conditions, we found it to be of interest to investigate several sources of vascular oxidative stress. Therefore we analysed the peripheral production of nitrotyrosine and iNOS as well as the lipid peroxidation activity, all known to be activated under diabetic conditions and to contribute to vascular damage [31]. As expected, and previously described, all measured indices of oxidative stress were markedly enhanced in untreated STZ rats in our model [32-34]. Whereas diabetes-induced increased nitrotyrosine and iNOS production were both attenuated nearly to levels in normoglycaemic conditions because of pharmacological enhancement of eNOS by AVE3085, the lipid peroxidation activity was not significantly reduced by the treatment, suggesting that vascular protection against hyperglycaemia by eNOS enhancement is at least in part mediated by attenuation of iNOS and nitrotyrosine overproduction.

Oxidative stress is known to induce intense vascular inflammatory response under diabetic conditions [35]. Furthermore, NO derived from eNOS is known to exert direct anti-inflammatory effects [35]. In addition, regarding the emerging role of inflammatory responses in the development of endothelial dysfunction and its attenuation because of $\mathrm{NO}$ release, we analysed peripheral production of the adhesion molecules ICAM-1 and VCAM-1. As has been shown previously [17], the inflammatory response in peripheral muscle tissue, as indexed by ICAM-1 and VCAM-1, was markedly increased under STZ-diabetic conditions. Adhesion molecules have attracted considerable attention because leucocyte adhesion and infiltration into the vessel wall were found to be crucial for initiating the inflammatory process [10]. Furthermore, we have already shown that enhanced diabetes-induced production of inflammatory markers like cytokines and cell adhesion molecules are associated with endothelial dysfunction [11], a fact which indicates the likelihood of a strong predictor of cardiovascular events [12]. In the present study, chronic treatment with AVE3085 reduced the inflammatory response in peripheral muscle tissue despite an unchanged occurrence of hyperglycaemia. This could be primarily caused by eNOS enhancement, but also indirect attenuation of the inflammatory response as a result of reduced oxidative stress might be a possible reason.

In conclusion, the present study shows that the novel compound AVE3085 significantly enhanced impaired eNOS production and NO-cGMP signalling in the hindlimb of severely diabetic animals. Subsequent beneficial effects included an improved endothelial function as well as a reduced vascular inflammatory response and oxidative stress.

Acknowledgements This study was supported by grants of the Deutsche Forschungsgesellschaft (DFG; GRK 865 to C. Tschöpe and P558/3-2 to H. Peters). We thank K. Puhl and N. Zingler for excellent technical assistance. We thank the native speaker M. Kastner (Academic Manuscripts, Berlin, Germany) for excellent manuscript revision.

Duality of interest The authors declare that there is no duality of interest associated with this manuscript. 


\section{References}

1. Ahern J, Grove N, Strand T et al (1993) The impact of the Trial Coordinator in the Diabetes Control and Complications Trial (DCCT). The DCCT Research Group. Diabetes Educ 19:509-512

2. Saenz de Tejada I, Goldstein I, Azadzoi K, Krane RJ, Cohen RA (1989) Impaired neurogenic and endothelium-mediated relaxation of penile smooth muscle from diabetic men with impotence. N Engl J Med 320:1025-1030

3. Nitenberg A, Valensi P, Sachs R, Dali M, Aptecar E, Attali JR (1993) Impairment of coronary vascular reserve and ACh-induced coronary vasodilation in diabetic patients with angiographically normal coronary arteries and normal left ventricular systolic function. Diabetes 42:1017-1025

4. McVeigh GE, Brennan GM, Johnston GD et al (1992) Impaired endothelium-dependent and independent vasodilation in patients with type 2 (non-insulin-dependent) diabetes mellitus. Diabetologia 35:771-776

5. Forstermann U, Munzel T (2006) Endothelial nitric oxide synthase in vascular disease: from marvel to menace. Circulation 113:1708-1714

6. Radomski MW, Palmer RM, Moncada S (1987) The role of nitric oxide and cGMP in platelet adhesion to vascular endothelium. Biochem Biophys Res Commun 148:1482-1489

7. Steiner M, Reinhardt KM, Krammer B, Ernst B, Blann AD (1994) Increased levels of soluble adhesion molecules in type 2 (noninsulin dependent) diabetes mellitus are independent of glycaemic control. Thromb Haemost 72:979-984

8. Oelze M, Mollnau H, Hoffmann N et al (2000) Vasodilatorstimulated phosphoprotein serine 239 phosphorylation as a sensitive monitor of defective nitric oxide/cGMP signaling and endothelial dysfunction. Circ Res 87:999-1005

9. Pieper GM (1998) Review of alterations in endothelial nitric oxide production in diabetes: protective role of arginine on endothelial dysfunction. Hypertension 31:1047-1060

10. Libby P (2002) Inflammation in atherosclerosis. Nature 420:868874

11. Tschope C, Walther T, Escher F et al (2005) Transgenic activation of the kallikrein-kinin system inhibits intramyocardial inflammation, endothelial dysfunction, and oxidative stress in experimental diabetic cardiomyopathy. FASEB J 19:2057-2059

12. Ganz P, Vita JA (2003) Testing endothelial vasomotor function: nitric oxide, a multipotent molecule. Circulation 108:2049-2053

13. Shah DI, Singh M (2006) Possible role of exogenous cAMP to improve vascular endothelial dysfunction in hypertensive rats. Fundam Clin Pharmacol 20:595-604

14. Nagareddy PR, Xia Z, MacLeod KM, McNeill JH (2006) $\mathrm{N}$-acetylcysteine prevents nitrosative stress-associated depression of blood pressure and heart rate in streptozotocin diabetic rats. J Cardiovasc Pharmacol 47:513-520

15. Komers R, Schutzer WE, Reed JF et al (2006) Altered endothelial nitric oxide synthase targeting and conformation and caveolin-1 expression in the diabetic kidney. Diabetes 55:1651-1659

16. Dorenkamp M, Riad A, Stiehl S et al (2005) Protection against oxidative stress in diabetic rats: role of angiotensin AT(1) receptor and beta 1-adrenoceptor antagonism. Eur J Pharmacol 520:179-187

17. Riad A, Unger D, Du J et al (2007) Chronic inhibition of p38MAPK improves cardiac and endothelial function in experimental diabetes mellitus. Eur J Pharmacol 554:40-45

18. Angulo J, Rodriguez-Manas L, Peiro C, Neira M, Marin J, SanchezFerrer CF (1998) Impairment of nitric oxide-mediated relaxations in anaesthetized autoperfused streptozotocin-induced diabetic rats. Naunyn Schmiedebergs Arch Pharmacol 358:529-537

19. Lorenz M, Jochmann N, von Krosigk A et al (2007) Addition of milk prevents vascular protective effects of tea. Eur Heart $\mathrm{J}$ 28:219-223

20. Van Linthout S, Riad A, Dhayat N et al (2007) Anti-inflammatory effects of atorvastatin improve left ventricular function in experimental diabetic cardiomyopathy. Diabetologia 50:1977-1986

21. Peters H, Wang Y, Loof T et al (2004) Expression and activity of soluble guanylate cyclase in injury and repair of anti-thy1 glomerulonephritis. Kidney Int 66:2224-2236

22. Riad A, Bien S, Gratz M et al (2008) Toll-like receptor-4 deficiency attenuates doxorubicin-induced cardiomyopathy in mice. Eur J Heart Fail 10:233-243

23. Sasaki K, Heeschen C, Aicher A et al (2006) Ex vivo pretreatment of bone marrow mononuclear cells with endothelial NO synthase enhancer AVE9488 enhances their functional activity for cell therapy. Proc Natl Acad Sci U S A 103:14537-14541

24. Hink U, Li H, Mollnau H et al (2001) Mechanisms underlying endothelial dysfunction in diabetes mellitus. Circ Res 88:E14E22

25. Smolenski A, Burkhardt AM, Eigenthaler M et al (1998) Functional analysis of cGMP-dependent protein kinases I and II as mediators of NO/cGMP effects. Naunyn Schmiedebergs Arch Pharmacol 358:134-139

26. Schafer A, Flierl U, Kobsar A, Eigenthaler M, Ertl G, Bauersachs J (2006) Soluble guanylyl cyclase activation with HMR1766 attenuates platelet activation in diabetic rats. Arterioscler Thromb Vasc Biol 26:2813-2818

27. Chereau D, Dominguez R (2006) Understanding the role of the G-actin-binding domain of Ena/VASP in actin assembly. J Struct Biol 155:195-201

28. De Vriese AS, Verbeuren TJ, Van de Voorde J, Lameire $\mathrm{NH}$, Vanhoutte PM (2000) Endothelial dysfunction in diabetes. Br J Pharmacol 130:963-974

29. Johnstone MT, Creager SJ, Scales KM, Cusco JA, Lee BK, Creager MA (1993) Impaired endothelium-dependent vasodilation in patients with insulin-dependent diabetes mellitus. Circulation $88: 2510-2516$

30. Targonski PV, Bonetti PO, Pumper GM, Higano ST, Holmes DR Jr, Lerman A (2003) Coronary endothelial dysfunction is associated with an increased risk of cerebrovascular events. Circulation 107:2805-2809

31. Haidara MA, Yassin HZ, Rateb M, Ammar H, Zorkani MA (2006) Role of oxidative stress in development of cardiovascular complications in diabetes mellitus. Curr Vasc Pharmacol 4:215-227

32. Moien-Afshari F, Ghosh S, Khazaei M, Kieffer TJ, Brownsey RW, Laher I (2008) Exercise restores endothelial function independently of weight loss or hyperglycaemic status in $\mathrm{db} / \mathrm{db}$ mice. Diabetologia 51:1327-1337

33. Menini S, Iacobini C, Ricci C et al (2007) Ablation of the gene encoding p66Shc protects mice against AGE-induced glomerulopathy by preventing oxidant-dependent tissue injury and further AGE accumulation. Diabetologia 50:1997-2007

34. Cameron NE, Eaton SE, Cotter MA, Tesfaye S (2001) Vascular factors and metabolic interactions in the pathogenesis of diabetic neuropathy. Diabetologia 44:1973-1988

35. Libby P, Nathan DM, Abraham K et al (2005) Report of the National Heart, Lung, and Blood Institute-National Institute of Diabetes and Digestive and Kidney Diseases Working Group on Cardiovascular Complications of Type 1 Diabetes Mellitus. Circulation 111:3489-3493 